\title{
EDITORIAL
}

\section{POSTGRADUATE MEDICAL EDUCATION}

The present constraints on financial support in general and on the military medical training organization in particular make it timely to review the current status and achievements of Army postgraduate medical education. A little over a year ago this important topic was discussed in these columns and the point was then made that the Army's programme of training in the hospital specialties and in general practice had received full recognition from the concerned civilian bodies ${ }^{1}$. An earlier editorial ${ }^{2}$, which described the evolution and implementation of the new speciality of Army Community and Occupational Medicine, laid emphasis on the requirement that every doctor joining the RAMC had to undertake further medical training in one form or another with the ultimate goal of completed vocational recognition for general practitioners or accreditation - or its equivalent for the specialties.

In the widest sense there is no doubt that the RAMC has been successful in achieving facilities for training of doctors, within and without the Service, that are at least as good as those in the National Health Service. It is however a fair criticism of Army training that equivalence of provision obtains up to and including accreditation but thereafter, in the field of continuation training the Army does less well. The NHS, in general terms, and perhaps rather more in principle than in practice, allows all consultants 30 days of study leave, including provision for approved overseas travel, every three years and similarly the target for general practitioners is 10 days a year. The Army does not do so well.

An essential element of Army postgraduate training, not emphasized in the earlier reviews is that dealing with preparation for the operational role and for war. All Army doctors are required, although sometimes they themselves tend to forget this requirement, to have a broad capability beyond the confines of their own speciality and in sharp contrast to current civilian practice where the trend is ever and inevitably towards increasing specialisation. Examples of what might be called this wider military medical professionalism can be culled from all the disciplines. The surgeon needs an extensive knowledge of missile injuries and of the care of mass casualties. The Army pathologist has to be expert on the science and mechanics of blood supply for the wounded; on immunization for all. The psychiatrist must know how to treat, early and effectively, psychiatric battle casualties. The physician has to be competent in the wide field of epidemic and exotic disease; in particular, as was demonstrated in Belize and Rhodesia ${ }^{3}$ there is a call for tropical medicine expertise. Above all, the primary care doctor needs to know something of all these specialist requirements and in addition he needs a comprehensive knowledge of occupational and environmental medicine if he is to cope with the many hazards which beset a soldier in peace or war, at home or overseas. This extrả learning is not achieved easily or quickly. It is not facilitated by the concentration of medical schools on hospital orientated practice and super specialization. 
In conclusion, the Army needs postgraduate medical education and needs it badly. It has to fulfil the dual task of achieving equivalence with the NHS and in no other way can the Army Medical Services care for its peacetime population of soldiers and their dependants - and of ensuring a thorough wideranging military medical professionalism that will provide the necessary competence and ability to deal with the threat of war medicine, whether it be this year, next year or sometime never.

\section{REFERENCE}

1. Anon. Postgraduate Medical Education. $J$ R Army Med Corps 1980; 126: 58.

2. Anon. A new speciality. $J R$ Army Med Corps 1979; 125: 57.

3. Anon. Tropical Medicine. $J R$ Army Med Corps 1980; 126: 2.

\section{QUEEN'S BIRTHDAY HONOURS LIST 1981}

KBE

CBE

BEM
Lt Gen H A J Reay, QHP

Col G Hall-Davis, TD, QHP, RAMC(V)

S/Sgt P J Hurstell. Sgt T Williams. S/Sgt L F Ferguson, RAMC(V)
REPRESENTATIVE COLONEL COMMANDANT RAMC

Brig W S Millar, LRCP, LRCS, FFCM, DIH, DPH, DTM\&H, late Royal Army Medical Corps (Retd), has been appointed Representative Colonel Commandant for 1982 . 